\title{
RPI and RPL clasp masticatory load distribution in lower free end denture case with photoelastic methods
}

\author{
Dahlia Sutanto, H. Muslich Mahmud, Poedji Rahajoeningsih \\ Department of Prosthodontics, Faculty of Dentistry Universitas Padjadjaran
}

\section{ABSTRACT}

The extent and direction of movement of removable partial dentures during function are influenced by the nature of supporting structures and the design of the prosthesis since forces are transmitted to abutment teeth by rest, guide planes, and direct retainers during functional movements. Because of the lack of tooth support distally, the denture base will have tissueward underfunction proportionate to the quality (displaceability) of the supporting soft tissue, the accuracy of the denture base, and the total occlusal load applied. The movement of the base under function determines the occlusal efficiency of the partial denture and the degree to which the abutment teeth are subjected to torque and tipping stresses. The purpose of this study is to know the functional load exerts with RPI and RPL direct retainer in bilateral distal extension. This study is a laboratory experiment employing samples of 5 frames using RPI and 5 frames using RPL direct retainer design. Testing was conducted by Vishay Teaching Polariscope type 080. The result was noted and analyzed statistically using ANOVA. The result of this study indicates that $\mathrm{F}$ calculation value for frame with RPI and RPL direct retainer design is 5,35 and 6,11 Mpa; F calculation for the occlusal load distribution on first premolar and edentulous area is $276,90 \mathrm{Mpa}$ and 171,53 Mpa; F calculation for occlusal load distribution on first premolar and edentulous area employing RPI and RPL direct retainer design is 9,17 and 11,96 Mpa. This statistical calculation shows that there is a significant difference between RPI and RPL direct retainer design, the occlusal load concentrated at edentulous area either RPI or RPL direct retainer, and the occlusal load distribution between the first premolar and edentulous area are more uniform on RPI direct retainer design.

Key words: Sodium Fluoride, chlorhexidine, aquadest, plaque index, fixed orthodontics

\section{INTRODUCTION}

According to The Glossary of Prosthodontics Terms, partial removable denture is any prosthesis that replaces several teeth on a part of dental arch that can be inserted and removed repeatedly. ${ }^{1}$ The parts of the prosthesis includes occlusal rest, major connector, minor connector, direct retainer, indirect retainer, supporting saddle, bracing components and balancing components.
Each component of the denture should be designed to gain maximum mechanical efficiency so the overall denture can function in a satisfactory manner. Clasps that hold, brace and support the partial denture in the mouth is one of the most important (critical) areas. The claps receive repeated masticatory stress, including during the insertion and removal of the denture for cleaning. Therefore, it is understandable that every mistake in designing or making denture will 
often create failures in the clasps. The successful partial denture mostly involves appropriate clasp selection. ${ }^{2}$

As stated by Mc Givney and Castleberry3; Boucher and Renner ${ }^{4}$ in designing clasps in certain condition, the function and limitations of the clasps should be attended and evaluated well. The clasps should be considered as a metal part of the denture frame and should be designed and placed to support their specific function for retention, stabilization, support, reciprocal, encirclement and passivity. ${ }^{2-6}$ Although there are several designs with various clasp arm designs and forms, the clasps can be categorized into two basic classifications. The first is the circumferential clasps, i.e. towards the undercut from the occlusal direction. The second is the bar clasp arm that moves towards the undercut from the gingival direction.

According to Kratochvil 7 , the success in distributing masticatory loads can be achieved through the use of RPI (Rest, Proximal plate, Ibar) clasps. By placing the retentive arm under the most convex point on the buccal surface of the anchorage tooth, this clasp can control torsion force on the tooth. Steffel ${ }^{8}$ suggested that the RPI clasp combination concept can reduce the concentration of masticatory loads in one site. ${ }^{2}$

This clasp consists of 3 parts, i.e.: (1) occlusal rest at the mesial part through the minor connector on the side of the anchorage tooth, (2) $\mathrm{I}$-formed retentive arm placed in the middle buccal surface of the anchorage teeth, and (3) vertical plate that contacts the distal and distolingual surface of the anchorage teeth. ${ }^{9,10}$

Besides RPI clasps, RPL (Rest, Proximal plate, L-bar) clasp is also available, often referred as One-half T-type bar clasp/modified T-Bar. According to Ben-Ur, et al. ${ }^{11}$ the effectiveness of the RPI system use can be improved when RPI clasp is replaced by RPL clasp. The occlusal rest position at the mesial and guide plate is the same as those designed for RPI clasp with I-bar replaced by L-shaped direct retainer that runs from the distobuccal saddle to the anchorage teeth. When L-bar is placed near or in line with the occlusal rest, L-bar will be free from the anchorage teeth when rotation experienced around the mesial occlusal anchorage. This clasp is also more esthetical because the retentive arm end is located more distal from the anchorage tooth buccal surface.,9,11 According to Ben-Ur, et.al. ${ }^{11}$ the advantages of Lbar clasp is more than I-bar clasp.

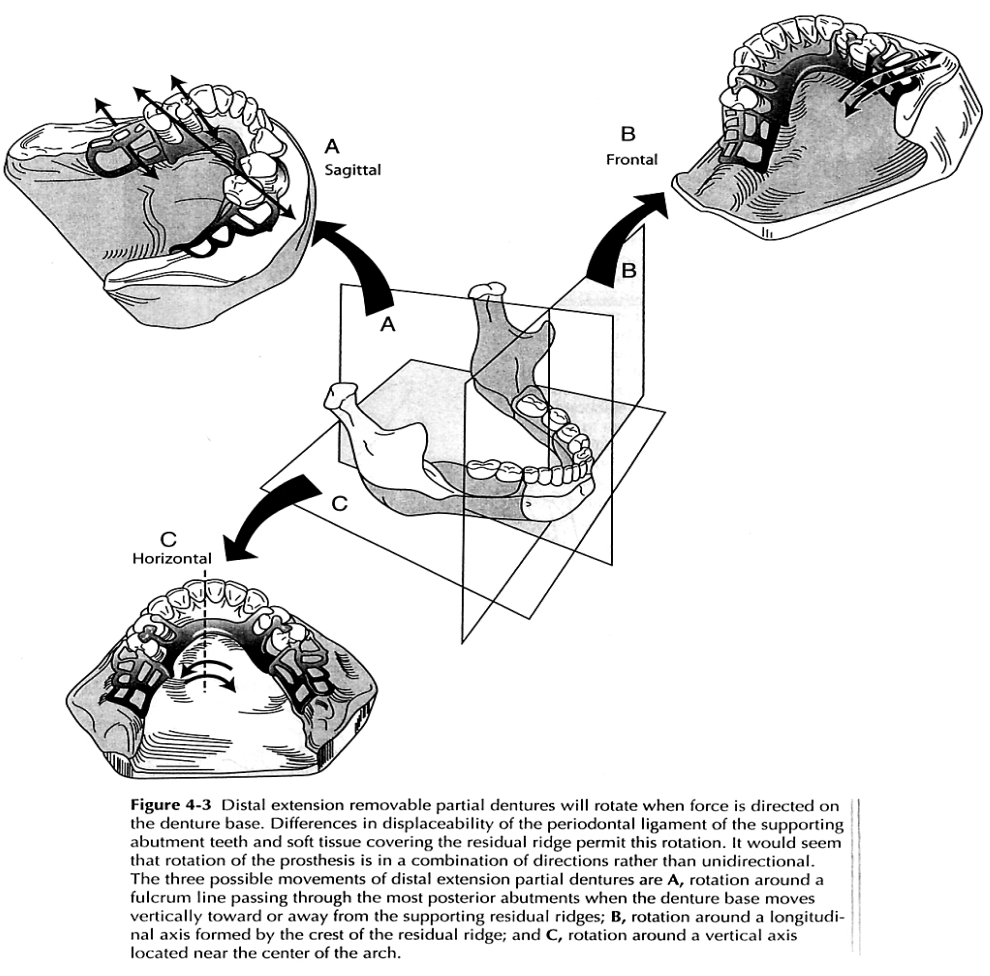

Figure 1. Free end denture movement.A. rotation on the fulcrum line across the most posterior anchorage tooth. B. longitudinal axis rotation along the posterior ridge peak. C. rotation on the imaginary axis perpendicular to the arch. 

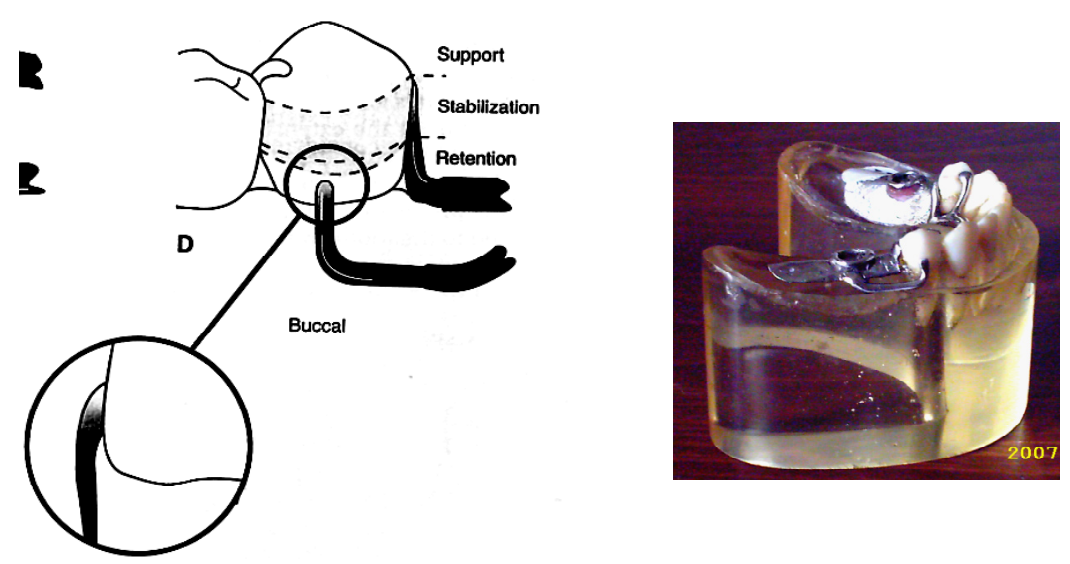

Figure 2. RPI clasp design (Mc Givney et al., 1995)

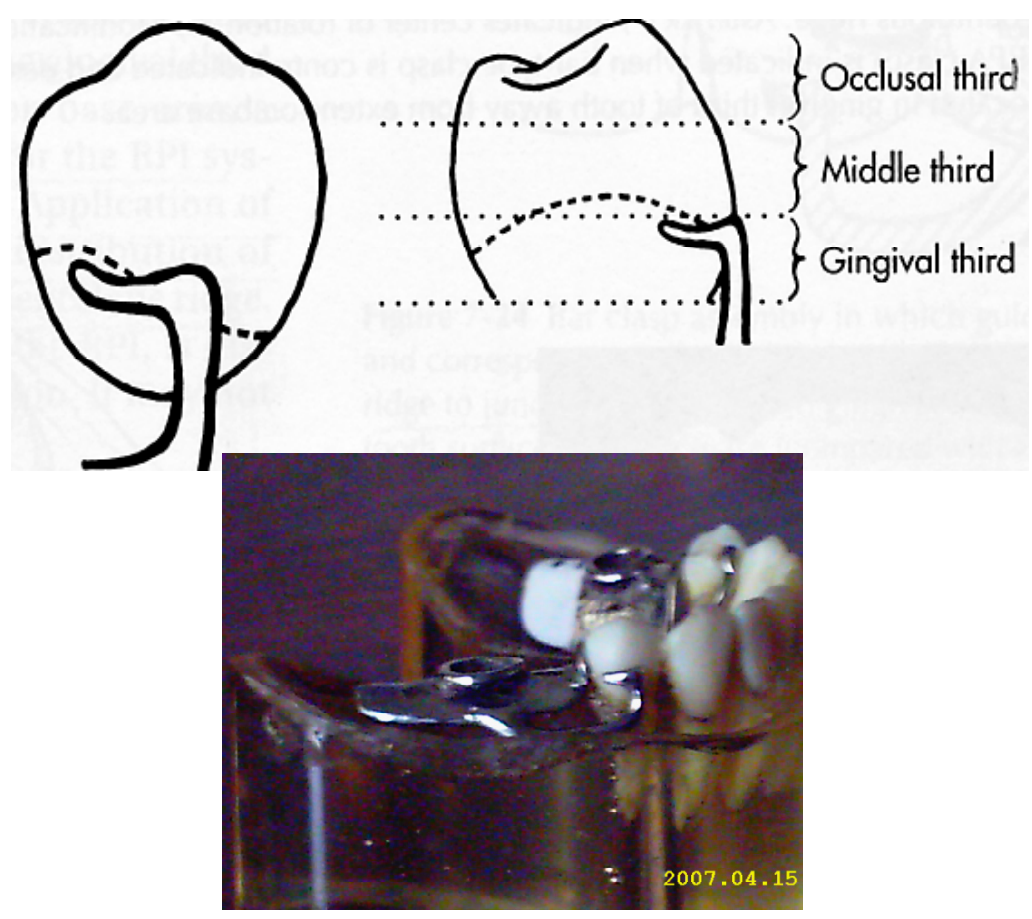

Figure 3. RPL clasp design.

Thompson, Kratochvill and Caputo et.al. ${ }^{12}$ suggested that masticatory load distribution using I-bar mesial rest with the load focused on the middle of the major connector shows that the occlusal load is concentrated near the ridge peak, the internal stress of the first premolar is almost evenly distributed with the tendency to be concentrated at the mesial near the ridge peak and root mesial surface. The supporting structures around the premolar teeth shows that the load is placed in the apical part with a deviation to the mesial that interacts with the canine apex and minimum canine involvement. ${ }^{12}$

Themasticatoryloaddistributionusingmesial rest- one-half T-bar and cast lingual retentive arm with the load concentrated in the middle of the major connector shows a load that is slightly even at the ridge area, even load distribution around the tooth with the concentration on the apical third. At the supporting tissues, especially on the first premolar apical part, there is a little deviation to the distal and interaction with the canines with a slight load at the canine apical third. ${ }^{12}$

Based on the above descriptions, with so many opinions from researchers on the clasp design that can provide masticatory load distribution to avoid overstressed tissue of the anchorage teeth and ridge, the author is interested to analyze the 
masticatory load distribution difference between RPI and RPL clasp design. The selection of these two designs is based on the considerations that: (1) From all existing bar claps, T-bar clasp, modified T-bar (2)(L-bar), and I-bar clasps are the most frequently used and the most simple clasps with satisfactory esthetic. ${ }^{4}$ (3) According to Z. Ben-Ur, et.al. ${ }^{11}$ and (anonymous) from Goa Dental College and Hospital ${ }^{9}$, the effectiveness of RPI (I-bar) clasp can be substituted by RPL clasp (L-bar). ${ }^{9,11}$ On the other hand, Krol and Kratochvil suggested that RPI is the most considered clasp to be selected for free end partial removable denture 7,11 (4) These clasps meet the requirements of a clasp because they give retention, stabilization, support, reciprocal, encirclement and passivity with satisfactory esthetics. ${ }^{4}$

This research is performed using a technique called photo elastics found by David Brewster in $1816 . .^{15}$ In this method, an optical instruments consist of the light source, polarisator and analysator to get the direction and tension pattern in the model. A model of the element to be tested is made from a transparent polymer and loaded according to the loading type. ${ }^{15}$

\section{Photo elastic basic theory}

The basic phenomenon in the photo elastic theory is the isotropic nature change into the anisotropic due to loading. This change changes causes phase differences on the light wave running through the model, so the tension line pattern occurs can be observed. ${ }^{15}$ Model to be tested is made from transparent polymer. The characteristic of the transparent polymer materials is that when the material is lighted by polarized light, a color pattern will occur. The location and distribution of this color layer (fringe order) shows the load location and distribution on the model. The more fringe order seen, the higher the load intensity in that part. ${ }^{5}$ The closer the distance between fringe orders, the higher the load concentration in that part. ${ }^{16}$

The criteria used in the photo elastic material selection are among the important factors in the photo elastic analysis because the ideal material does not exist. Therefore, the most suitable material for the need should be selected from the available materials. ${ }^{16}$ The testing tool for tension analysis with transparent photo elastic method is polariscope. The polariscope is an optical device using polarized light nature in its operation. ${ }^{15}$ The photo elastic method is used because this technique gives visual display of the load received by the anchorage teeth, remaining ridge and is able to show the load that can be read on each point in terms of the direction and the size of the load. ${ }^{21}$ Besides, several elements of the research and the condition can also be used to visualize load occurs in the model. ${ }^{18}$

\section{METHOD}

The type of this research is a pure laboratory experiment towards the masticatory load distribution in the first premolar and first molar (ridge) on the lower free end partial denture with a clasp design using occlusal rest on the RPI and RPL mesial through photo elastic technique.

The samples are 10 metal frames that consist of 5 metal frame with an occlusal rest on the mesial RPI design and 5 metal frames with RPL design.The ten metal frames (one by one) are placed on a free end model that includes 6 anterior teeth and 2 lower first premolars (a week after extraction) so that the form and size is almost similar. The teeth are in good conditions. No caries, fracture and enamel abnormality. Before they are invested, the teeth are soaked in a saline solution until the making of the model.

Research equipment: (1) Vishay Teaching (Measurement Group, USA), (2) Over Head Projector (OHP), (3) Loading instrument and load cell, (4) Wheatstone bridge, (5) Interface multi-channel,(6) Computer (7) Dynamic Strain Amplifier, (8) Digital camera, (9) Contra angle high speed, (10) Rubber bowl and spatula,(11) methylated spirit light, (12) Lecron, tweezers and dental probe.

Research materials: (1) Six lower anterior teeth and 2 lower first premolar teeth with rest seat at the mesial part, (2) Silicon rubber impression material, (3) Elastic type Lycal Resin (DongGuan Haoli Fine Chemicals Ltd), (4) Polyurethane A and Polyurethane B (periodontal ligament simulation), (5) Chrome Cobalt Wironit extrahard metal (Bego), (6) Reversible hydrocolloid gel, (7) Heat-proof Biosint Supra investment material (Degudent 
GmbH, Germany), (8) Wax pattern (Dentaurum, Germany), (9) Base plate wax, (10) Stone plaster.

\section{Steps for making study model and metal frame}

Steps for making study model: (1) Make impression for bilateral free end model, (2) Pour

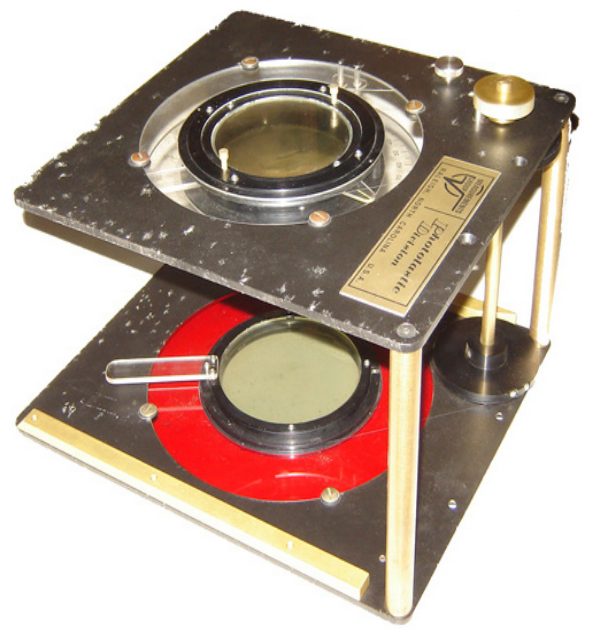

Figure 4. Vishay Teaching Polariscope 080 series.

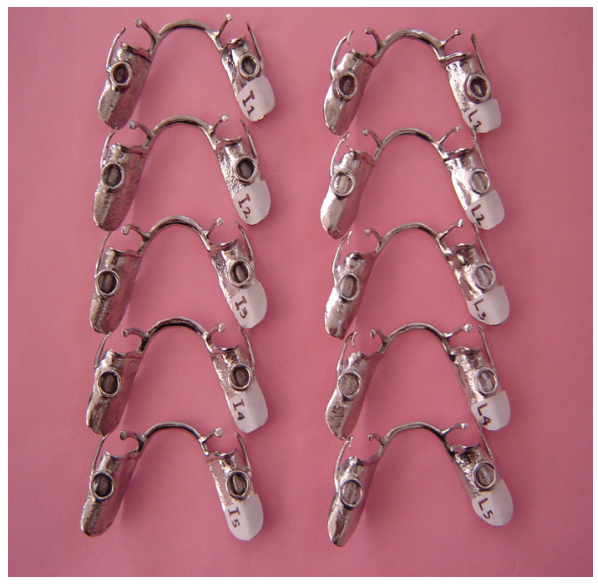

Figure 5. Study Samples.

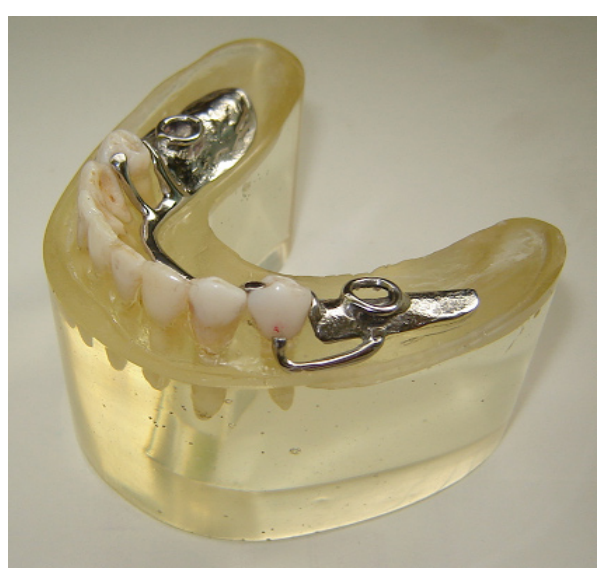

Figure 6. Metal frame on the study model. the impression with stone plaster, (3) Arrange 3444 teeth on the study model, (4) Duplicate study model, (5) Mix elastic Lycal resin: harderner $=2$ $\mathrm{ml}: 1 \mathrm{ml}$ according to manufacturer's instruction,

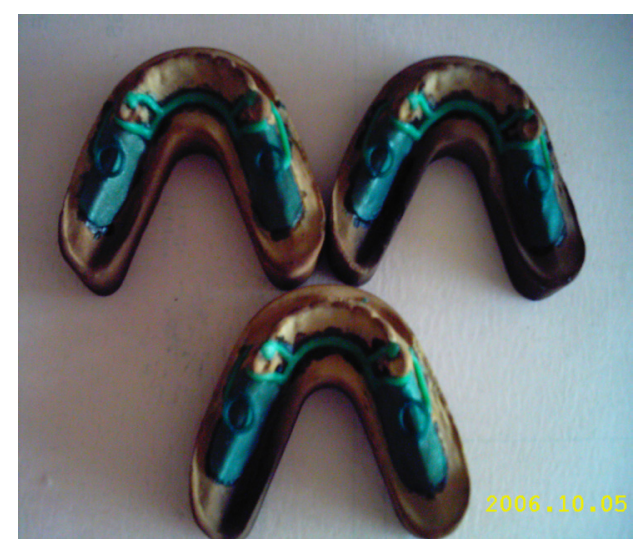

Figure 7. Wax pattern on study models

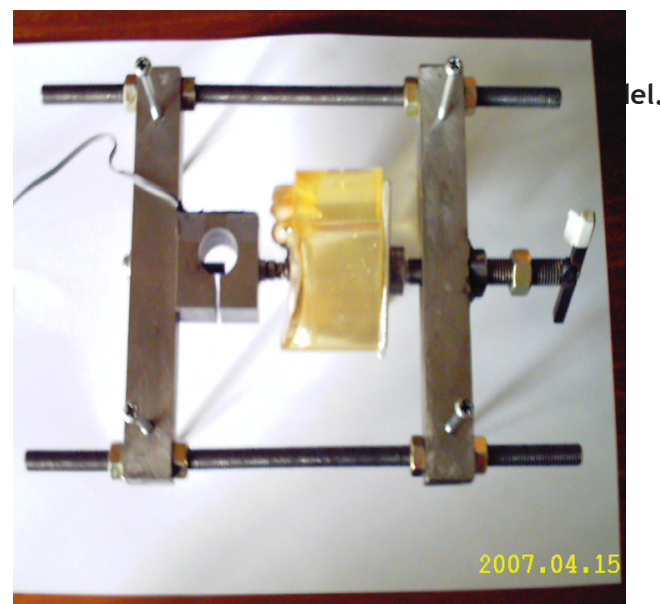

Figure 8. Model on the loading instrument.

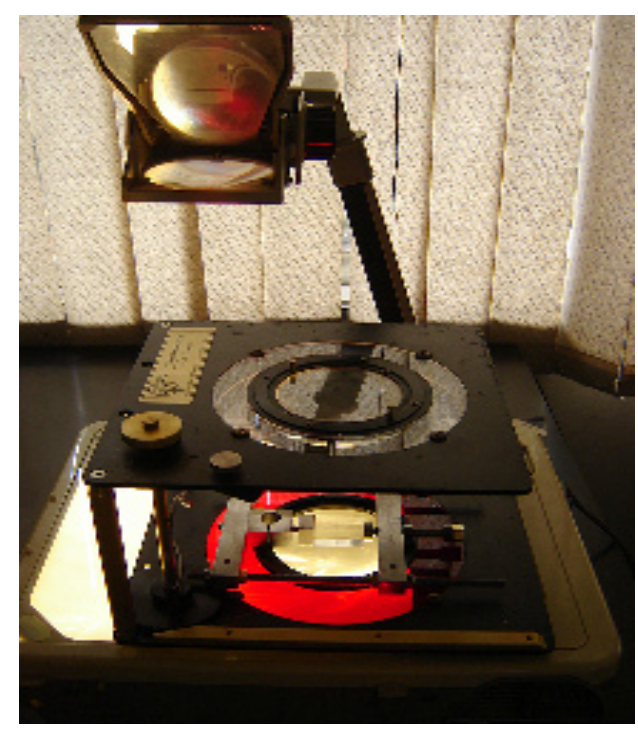

Figure 9. Model and loading instrument between two polariscope wave plates located on the OHP. 


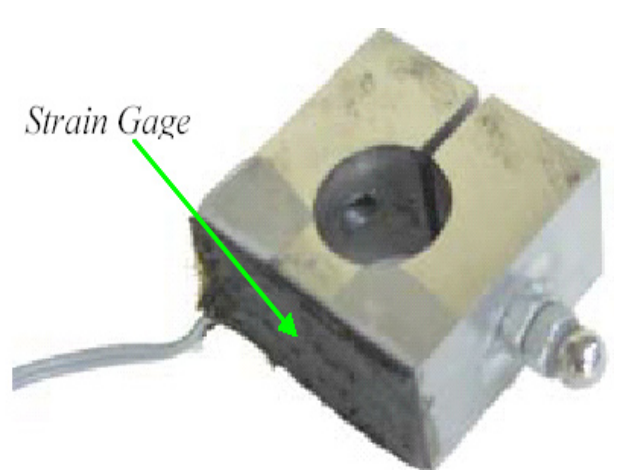

Figure 10. Loadcell.

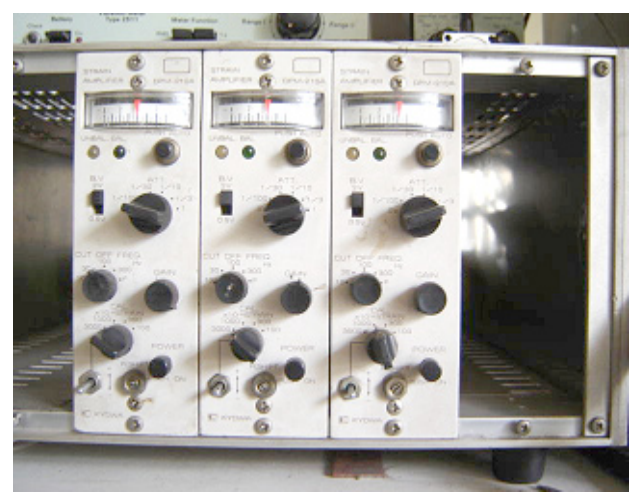

Figure 11. Dynamic strain amplifier.

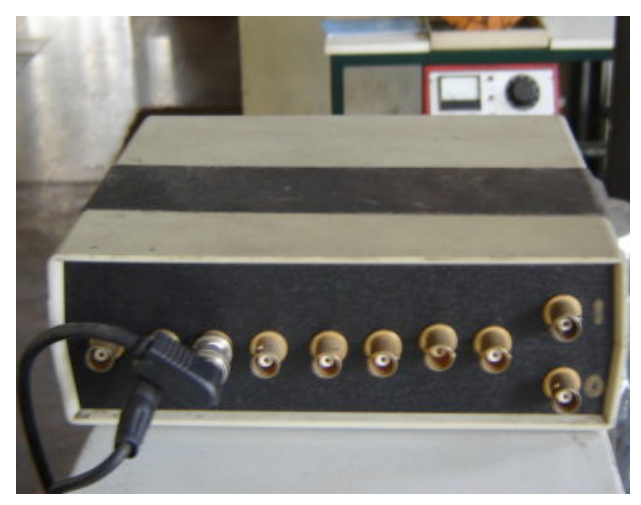

Figure 12. Interface.

(6) After Lycal resin hardened, remove Lycal resin filled model from the mold silicon rubber, (7) Prepare occlusal rest at the mesial part of the lower right first premolar and left first premolar using diamond bur.

Steps for making metal frame: (1) Duplicate elastic Lycal resin transparent/study model, (2) Pour with stone plaster for 10 study models to make 10 metal frames, (3) Two of 10 stone study models are duplicated using reversible hydrocolloid gel for making 2 metal frames with each design first, (4) Place the metal frame on study model and then duplicate it with reversible hydrocolloid gel, (5) Pour with Bisont Supra stone. The cast result after the metal frame is removed will have the metal frame borders imprinted, (6) Burn and dip model into hardener solution, (7) Place wax pattern on the study model, (8) Place sprue, invest, remove wax, cast, and burnish, (9) Place metal frames (one by one) on the clear elastic Lycal resin model/study model.

Management of model using study supporting tools: (1) Place metal frame on the clear elastic Lycal resin model (study model) and place it into the loading equipment. The model base is situated on the plate on the pressing thread. The first molar region (ridge) is pressed using a ball bearing with a diameter of $6.35 \mathrm{~mm}$ to focus loading, (2) Mount study model and loading instrument between two wave plates on the polariscope located above the OHP as the light source, (3) The amount of stress load given by the pressing thread to the loading instrument can be learned through load cell on the loading instrument. The load cell receives similar force as the one received by the study model. On the load cell, a strain gauge is installed to change strain changes in the load cell into electric resistance change, (4) Connect load cell and strain gauge to the dynamic strain amplifier through Wheatstone bridge to change resistance into an electric voltage, (5) Connect the dynamic strain amplifier to the interface. The signal comes out from the dynamic strain amplifier is an analogue signal. The interface is the Analog to Digital Converter (ADC) instrument that functions to change the analogue signal into the digital signal which is then inputted into the computer through a module/card installed on the main board to be processed digitally. The signal processing needs a software to display the measurement results, i.e. Software Labtech Control.

\section{Tests for study model}

Each metal frame is given the same loads by doing stressing for 3 times with 5 minute intervals and by using 2 types of weights $1.2921 \mathrm{kgf}(=1.3$ $\mathrm{kgf})$, where in this lode the maximum fringe order number that can be observed is 3 orders and with a load of $2.8899 \mathrm{kgf}(=3 \mathrm{kgf})$ with the maximum fringe order number can be observed is 6 orders. With a load of $1.3 \mathrm{kgf}$ pressure thread spun a half spins while in $3 \mathrm{kgf}$ load the pressure thread is spun three quarter spin. 
The steps in study model test with a load of $1.3 \mathrm{kgf}$ and $3 \mathrm{kgf}$ : (1) Place metal frame on the study model, (2) Mount study model on the loading instrument, (3) Place study model with loading instrument between 2 wave plates on the polariscope above the OHP, (4) Give incremental load until the computer screen shows loads wanted, (5) Fringe order description is photographed using a digital camera, (6) Stop loading and rest the model for 5 minutes, (7) Stage 1 to stage 7 is performed to all metal frames.

The photo results from the digital camera are transferred to the computer to make the isochromatic line pattern easier in the first premolar and first molar (ridge) region. The results are then recorded and entered into a formula called optical tension law that results in masticatory load distribution result in Mega Pascal unit (Mpa) (Burger, 1987). ${ }^{15}$

$$
\sigma_{1}-\sigma_{2}=\frac{N f \sigma}{h}
$$

$\sigma_{1}, \sigma_{2}=$ main tension $\sigma_{1}>\sigma_{2}$ with $\sigma_{2}$ considered as zero $\left(\mathrm{N} / \mathrm{mm}^{2}\right.$ or $\left.\mathrm{Mpa}\right)$

$\mathrm{N}=$ fringe order (photo elastic order)

$f \sigma=$ material fringe score $=0.416 \mathrm{~N} / \mathrm{mm}$

$h=$ material thickness $=21.5 \mathrm{~mm}$

Fringe order interpretation: (1) The photo results are transferred into the computer, (2) Determine order in the first molar region (ridge). Determine fringe order starting from the area that does not receive loading marked by black, grey, white, yellow, orange, and red isochromatic line. This color pattern includes into zero order (0) according to the isochromatic order table. ${ }^{30}$ (a) Entering order 1, after the red isochromatic line pattern, the blue color will appear. After that, the blue color will be followed by blue-yellow, orange and red, (b) Entering order 2, after the red isochromatic line pattern, green color will appear. Next, the green color will be followed by greenyellow and pink, (c) Entering order 3, after pink isochromatic line pattern, green color will appear. After green, pink follows. Based on the table, the number of colors appear is less with the higher fringe order. The higher the fringe order, the color will only consists of green and pink (starting from fringe order 4. 4), (d) Fringe order interpretation is continued until the nearest fringe order closest to the load center in the first molar region (ridge), (3) Determine order in the first premolar region. Isochromatic line is a continuous band, making a loop or winding line, starting and ending at the band and never crosses between one isochromatic line and the others.

Interpreting isochromatic line pattern in the first premolar region starts at the isochromatic line that is a continual of the isochromatic line pattern from the ridge to the first premolar apex without being interrupted.

\section{Data analysis}

The results of the research is tested statistically using variant analysis to learn the masticatory load distribution on lower first premolar and free end ridge by using occlusal rest on mesial RPI and RPL.

Table 3.9. Isochromatic order

\begin{tabular}{cc}
\hline Colour & Orde $(\mathbf{N})$ \\
\hline Black & 0 \\
Grey/Ask & 0.28 \\
White & 0.45 \\
Yellow & 0.60 \\
Pink & 0.80 \\
Red & 0.90 \\
1'Tint $^{\text {stint }}$ & 1.00 \\
Blue & 1.08 \\
Blue-Green & 1.22 \\
Green-Yellow & 1.39 \\
Pink & 1.63 \\
Red & 1.82 \\
2nd Tint $_{\text {Green }}$ & 2.00 \\
Green-Yellow & 2.35 \\
Pink & 2.50 \\
3 $^{\text {rd }}$ Tint & 2.65 \\
Green & 3.00 \\
Pink & 3.10 \\
4 $^{\text {thint }}$ & 3.65 \\
\end{tabular}

\section{RESULT AND DISCUSSION}

The results in table 4.1 and 4.2 above show a different in masticatory load distribution RPI and RPL. This is in line with Thompson, et. al. statement that the masticatory load distribution using RPI is concentrated near mesial ridge peak, mesial root, even distribution of internal stress on the first premolar while with RPL the distribution is slightly evenly distributed on the ridge, concentrated at the apical third, deviation to the distal part and interact with the canines. ${ }^{8}$ 

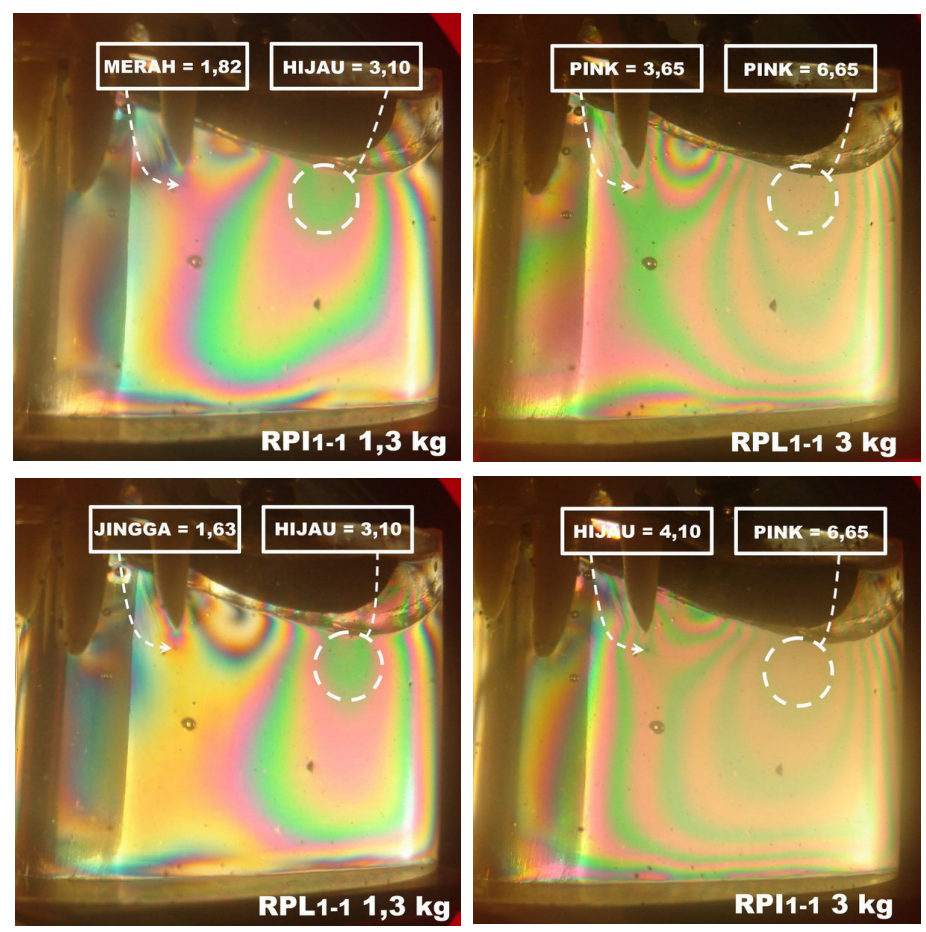

Figure 13. Fringe order description

Results on table 4.1 and 4.2 above show that the masticatory load is concentrated on the ridge either in RPI or RPL.This is in accordance with $\mathrm{Kratochvil}^{7}$ statement and Krol that suggests placing occlusal rest on the main mesial anchorage teeth on the free end denture. This situation makes more support from the ridge possible. ${ }^{3}$ The same is also stated by Shifman et.al. ${ }^{19}$ that stated that the main attention of the free end denture is to control torsion forces experienced by the anchorage teeth and to maximize the ridge support by performing muscle trimming and functional impression for altered cast making procedure. According to Mizuuchi et.al. ${ }^{24}$ by placing occlusal rest at the mesial part the anchorage teeth migration to the distal will be decreased and the denture saddle movement is also reduced. ${ }^{20}$

Results of table 4.1 and 4.2 above show that the masticatory loading distribution for RPI design is more even/balanced. This is in line with Kratochvil statement that the masticatory load distribution to the whole oral tissue can minimize the effect of functional load on one anchorage tooth or ridge. Therefore, Steffell ${ }^{8}$ suggested that the combination concept with occlusal rests at the mesial, guide place, I-bar will decrease the concentration of the masticatory load on one site only.
According to Clayton and Jaslow22, the clasp design using wires will create greater force in anchorage teeth compared to bar clasp from cast metal. This relates to the basic principle in designing clasp: principle of encirclement where the bar clasp include the tooth more than $180^{\circ}$ on the occlusal rest, retentive arm on the buccal surface and plate proximal contacts the distal and distolingual surfaces of the anchorage teeth..$^{8,22}$

According to Nakamura et. al..$^{23}$ in the partial denture masticatory load distribution using magnet hook, the magnet hook design gives the most even load distribution either in the unilateral or bilateral loading, similar to RPI clasp. This relates with the decrease anchorage tooth crown and root comparison because the magnet hook is situated under the gingival crest. ${ }^{23}$

The masticatory loading distribution between the anchorage teeth with the ridge in the design using occlusal rest on the mesial RPI is more even/balanced. This situation shows that the biomechanical behavior of the denture is better and this is in accordance with $\mathrm{Kratochvil}^{7}$ who controls functional movement of the partial denture with RPI clasp. This concept emphasizes the masticatory loading distribution to all oral tissue by reducing the effect of the functional load on one anchorage tooth or ridge. ${ }^{2}$ 
Table 1. Load distribution average value on the first premolar and ridge using RPI and RPL design with $3 \mathrm{kgf}$ load (Mpa).

\begin{tabular}{|c|c|c|c|c|}
\hline \multirow{2}{*}{$\begin{array}{l}\text { Frames } \\
\text { (A) }\end{array}$} & \multicolumn{2}{|c|}{ Gigi } & \multirow[t]{2}{*}{ Total } & \multirow[t]{2}{*}{ Average } \\
\hline & Premolar (Mpa) & Linggir (Mpa) & & \\
\hline - & 0.079330 & 0.059981 & - & - \\
\hline - & 0.089972 & 0.059981 & - & - \\
\hline RPI & 0.070623 & 0.070623 & - & - \\
\hline - & 0.089972 & 0.059981 & - & - \\
\hline - & 0.079330 & 0.070623 & - & - \\
\hline Total & 0.217095 & 0.321189 & 0.538284 & - \\
\hline Average & 0.043419 & 0.064238 & - & 0.053828 \\
\hline Tsd & 0,0045862 & 0,0058289 & - & - \\
\hline - & 0.031539 & 0.059981 & - & - \\
\hline - & 0.031539 & 0.070623 & - & - \\
\hline RPL & 0.026895 & 0.070623 & - & - \\
\hline & 0.031539 & 0.070623 & - & - \\
\hline- & 0.031539 & 0.059981 & - & - \\
\hline Total & 0.153051 & 0.331831 & 0.484882 & - \\
\hline Average & 0.030610 & 0.066366 & - & 0.048488 \\
\hline Std & 0,0020769 & 0,0058289 & - & - \\
\hline Total & 0.370146 & 0.653020 & 1.972613 & - \\
\hline Average & 0.037015 & 0.653020 & . & 0.051158 \\
\hline
\end{tabular}

Table 2. Load distribution average value on the first premolar and ridge with RPI and RPL design using $1.3 \mathrm{kgf}$ (Mpa) load.

\begin{tabular}{ccccc}
\hline \multirow{2}{*}{ Frames (A) } & \multicolumn{2}{c}{ Tooth (B) } & Total & Average \\
\cline { 2 - 3 } & Premolar $(\mathrm{Mpa})$ & Ridge (Mpa) & & \\
\hline- & 0.035215 & 0.059981 & - & - \\
RPI & 0.045470 & 0.059981 & - & - \\
- & 0.045470 & 0.070623 & - & - \\
- & 0.045470 & 0.059981 & - & - \\
Total & 0.045470 & 0.070623 & - & - \\
Average & 0.217095 & 0.321189 & 0.538284 & - \\
Tsd & 0.043419 & 0.064238 & - & 0.053828 \\
- & 0,0045862 & 0,0058289 & - & - \\
- & 0.031539 & 0.059981 & - & - \\
RPL & 0.031539 & 0.070623 & - & - \\
- & 0.026895 & 0.070623 & - & - \\
- & 0.031539 & 0.070623 & - & - \\
Total & 0.031539 & 0.059981 & - & - \\
Average & 0.153051 & 0.331831 & 0.484882 & 0.048488 \\
SD & 0.030610 & 0.066366 & - & - \\
Total & 0,0020769 & 0,0058289 & - & - \\
Average & 0.370146 & 0.653020 & 1.023166 & 0.051158 \\
\hline
\end{tabular}

Table 3. The hypothesis test result using variant analysis (load $=3 \mathbf{k g f})$

\begin{tabular}{ccccccc}
\hline Variation sources & $\mathbf{d k}(\mathbf{d f})$ & $\begin{array}{c}\text { Quadrat } \\
\text { Number }\end{array}$ & $\begin{array}{c}\text { Average of Quadrat } \\
\text { Number }\end{array}$ & $\mathrm{F}$ count & $\mathrm{F}$ table 0.05 & Significance \\
\hline Average & 1 & 0,19456 & - & - & - & - \\
Action & - & - & - & - & - & - \\
Frame (A) & 1 & 0.00024 & 0.00024 & -35 & 4.49 & - \\
Tooth (B) & 1 & 0.01222 & 0.01222 & 276.90 & 4.49 & - \\
Interaction AB & 1 & 0.00040 & 0.00040 & - & - & - \\
Error & 16 & 0,00071 & 0.00004 & - & - & - \\
Total & 20 & 0.21 & - & - & - \\
\hline
\end{tabular}

Onthe otherhand, amongseveral researchers who have stated that RPI is the best clasp for free end denture there are some researchers who have the opinion that the RPI clasp can be replaced by RPL just as stated by Ben-Ur. ${ }^{11}$ and (anonymous) from Goa Dental College and Hospital India. ${ }^{9}$
The rationale of Ben-Ur. ${ }^{11}$ opinion is viewed from the location of the retentive arm end at the most distal surface when receiving loading since the RPL clasp retentive end will be detached from the tooth surface. Meanwhile the I-bar retentive bar arm end will be placed more apical and closer 
to occlusal rest then the I-bar retentive arm end will move more to anterior when the saddle receive loads. ${ }^{11}$

According to Cecconi et.al. ${ }^{24}$, the anchorage tooth migration is bigger in I-bar design and this may caused by the I-bar design in the Cecconi study does not use guiding plane at the distal part because the guiding plane is very important in the I-bar concept. ${ }^{8}$ Several authors suggest putting occlusal rest at the mesial because such design will reduce load on the anchorage teeth. According to Kapur et.al ${ }^{25}$. in his 5 year clinical research, there is no influence on the anchorage teeth of free end partial removable denture using RPI or circumferential clasp with occlusal rest at the distal (E-type).

Table 4 The hypothesis test result using variant analysis $(1.3 \mathrm{kgf})$

\begin{tabular}{|c|c|c|c|c|c|c|}
\hline $\begin{array}{l}\text { Variation } \\
\text { sources }\end{array}$ & $\begin{array}{l}d k \\
(d f)\end{array}$ & $\begin{array}{l}\text { Quadrat } \\
\text { Number }\end{array}$ & $\begin{array}{c}\text { Average of } \\
\text { Quadrat Number }\end{array}$ & $\underset{\text { count }}{F}$ & $\begin{array}{c}F \\
\text { table } 0.05\end{array}$ & Significance \\
\hline Average & 1 & 0,05234 & - & - & - & - \\
\hline Action & - & - & - & - & - & - \\
\hline Prame (A) & 1 & 0.00014 & 0.00014 & 6.11 & 4.49 & $\left.{ }^{*}\right)$ \\
\hline Tooth(B) & 1 & 0.00400 & 0.00400 & 171.53 & 4.49 & $\left.{ }^{*}\right)$ \\
\hline Interaksi AB & 1 & 0.00028 & 0.00028 & 11.96 & 4.49 & $*$ \\
\hline Error & 16 & 0,00037 & 0.00002 & - & - & - \\
\hline Total & 20 & 0.06 & $\begin{array}{c}-002 \\
-\end{array}$ & - & - & - \\
\hline
\end{tabular}

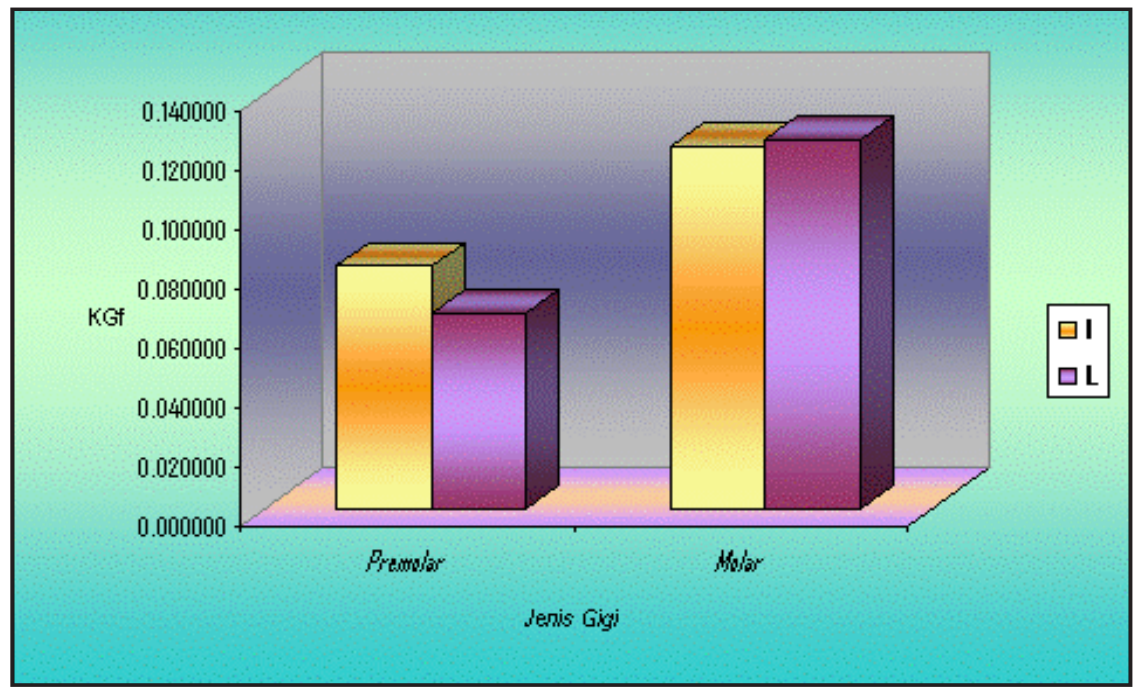

Diagram 1. Masticatory loading distribution First premolar and ridge (3kgf)

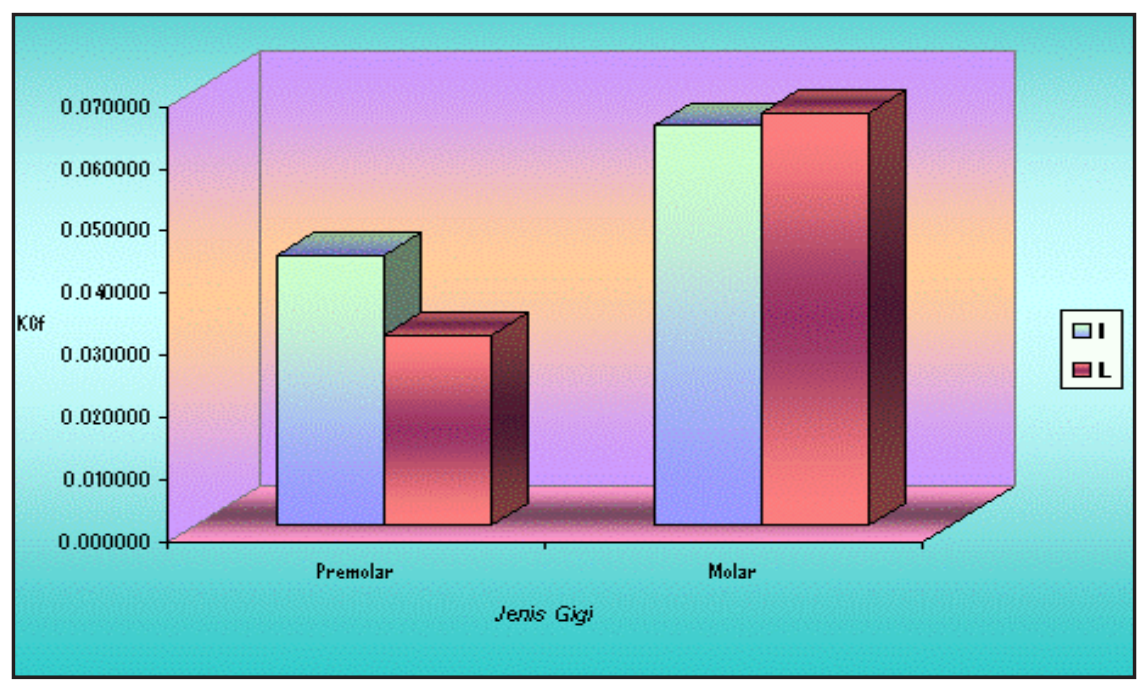

Diagram 2. Masticatory loading distribution first premolar and ridge (1.3 kgf) 
The depth of RPI and RPL clasp undercut in this study is 0.01 inch which is similar to the clasp requirements. According to Thompson, et.al. ${ }^{12}$, if the retentive arm of the clasp is placed in a deeper undercut, it can create bigger load pattern with different size and location. The same is true for thicker clasp when making wax model that may create bigger pressure because the elasticity is reduced. ${ }^{12}$

The load distribution analysis can be performed through photo elastic technique or finite element. The finite element technique is a technique that uses computer simulation through software while the photo elastic technique requires the making of models from the element to be tested. This photo elastic technique has been used broadly and successfully in the dentistry field to learn the interaction of soft tissue with the prosthetic restorative or implant physical natures. ${ }^{26,27}$

The type of this research is the pure/ in vitro laboratory experimental so that the author experienced some difficulties in making a study model in terms of selecting materials. Material selection is one of the important factors in the photo elastic analysis because there is no ideal material so the material should be selected according to the need from the available materials. The criteria of the photo elastic material include: the model material should be transparent, has a high sensitivity so that it can give more isochromatic lines in similar loading and has optical nature. ${ }^{15}$ With this criteria, when it is exposed to polarized light, the material will give isochromatic line pattern description. The material used in this research is the elastic Lycal resin to simulate alveolar bone while the teeth used are natural teeth. These materials are chosen because they meet the abovementioned criteria.

Another difficulty experienced in this study is that the available polariscope is generally used for a two dimension model while the study model is in three dimensional form. Therefore, it is necessary to make a loading instrument according to the need and modify the polariscope without reducing the accuracy of the results gained from the study by replacing the supporting post in the polariscope so that the study model and loading instrument can be placed between the two wave plates in the polariscope.

\section{CONCLUSION}

The advantageous loading distribution resulting from clasps that use occlusal rest in the mesial RPI is because the masticatory loading distribution between the anchorage teeth with the ridge is more even/balanced compared to the RPL clasp. This clasp has a better esthetic with less tooth surface contacts the metal so it only slightly or not influence the tooth form. Placing occlusal rest more anterior/mesial on the free end partial removable denture will give a rotation axis that direct the forces experienced more to the vertical/long axis of the tooth. ${ }^{8} \quad \mathrm{D} \mathrm{i} \mathrm{re} \mathrm{C} \mathrm{t}$ retainer for free end partial removable denture should be determined after a careful evaluation on the patient's condition, consideration of the clasp benefit and contra indication in each clasp design. Clasp that is determined based on the basic principles on designing denture will guarantee the success of the partial removable denture and the prognosis of the denture supporting tissue. The selection of direct retainer for the free end partial removable denture has created discussions among researchers in various articles and invite interests among dentists for years.

\section{REFERENCES}

1. The Glossary of Prosthodontics Terms. $7^{\text {th }}$ ed. St Louis: Mosby Inc; 1999. p. 55:67-960.

2. Planned partial. USA: The Ney Co. 1955.p. 102.

3. Mc Givney GP, Castleberry DJ. Removable partial prosthodontics. $11^{\text {th }}$ ed. USA: RR Donnely and Sons Co.; 1995. p. 8-9,25-6,28$31,35,79-81,83-92,101,107,142,145,149$ $50,55,287,288-92,293-9,331$.

4. Boucher LJ, Renner RP. Treatment of partially edentulous patients. London: Mosby Inc.; 1982. p. $15,32-4,36,44,56,64-5,71-2,74-5,79,88$.

5. Mahmud M. Pola perencanaan gigi tiruan sebagian lepasan kerangka logam. J Ked Gigi FKG UNPAD 2001;1-2:38-48.

6. Cho GC, Donovan TE. Esthetic consideration with removable partial denture. J Calif Dent Assoc 2003:1-12.

7. Krathofill. In: Johnson DL, Stratton RJ. Fundamental of removable prosthodontics. Chicago: Quintessence Publishing Co. 1980. p. 
$83,87,92,125,127,135,140,147,271$.

8. Steffel. In: Johnson DL, Stratton RJ. Fundamental of removable prosthodontics. Chicago: Quintessence Publishing Co. 1980. p. $83,87,92,125,127,135,140,147,271$.

9. Extracoronal direct retainer for distal extension removable partial dentures. J Indian Prosthod Soc 2005;5(2):65-71.

10. Lechner SK, Mac Gregor AR. Removable partial prosthodontics. Great Britain: Wolfe Publishing; 1994. p. 43.

11. Ben-Ur Z, Aviv I, Cardash HS. A modified direct retainer design for distal extension reovable partial denture. J Prosthet Dent 1988;60(3):324-44.

12. Thompson WD, Kratochvil FJ, Caputo AA. Evaluation of photoelastic stress patterns produced by various design of bilateral distalextension removable partial dentures. J Prosthet Dent 2004;91(2):105-113.

13. Stratton RJ, Wiebelt FJ. An atlas of removable partial denture design. Chicago, Illinois: Quintessence Publish Co.Inc.; 1988. p. 12.

13. Brewer AA, Morrow RM. Overdenture. $2^{\text {nd }}$ ed. St. Louis: Mosby Co; 1980. p. 365.

14. Mahyuddin AL. Analisa tegangan flens Poros dengan metoda fotoelastisitas. Tugas Sarjana Program Studi Teknik Mesin. Bandung: FTI-ITB; 1984. p. 4,8,15,49.

15. Ochiai KT, Ozawa S, Caputo AA. Photoelastic stress analysis of implant-tooth connected prostheses with segmented and nonsegmented abutment. J Prosthet Dent 2003;89:495-502.

16. KoSH, McDowellGC, KotowiczWE. Photoelastics stress analysis of mandibular removable partial denture with mesial and distal occlusal rests. J Prosthet Dent 1986;56:454-60

17. Nishimura RD, Ochiai KT, Caputo AA, et al. Photoelastics stress analysis of load transfer to implants and natural teeth comparing rigid and semirigid connectors. J Prosthet Dent1999;696-703.
18. Shifman A, Ben-ur Z. The Mandibular first premolar as an abutment for distalextension removable partial denture: a modified clasp assembly design. J British Dent 2000;188(5):246-48.

19. Mizuuchi $W$, Yatabe $M$, Sato $M$, et al. The effect of loading locations and direct retainers on the movements of the abutment tooth and denture base of removable partial denture. J Med Dent Sci, 2002;49(1):1-8.

20. Johnson DL, Stratton RJ. Fundamental of removable prosthodontics. Chicago: Quintessence Publishing Co. 1980. p. 83,87,92 ,125,127,135, 140,147,271.

21. Clayton. In: Ardan R. Disain gigi tiruan sebagian lepasan berujung bebas akrilik sederhana. Proceeding Scientific Meeting in Dentistry IPROSI I; Bandung, Indonesia; 2007. p. 157162.

22. Nakamura $\mathrm{Y}$, Nakamura $\mathrm{H}$, Ochiai $\mathrm{KT}$, et al. Comparison of load transmission by removable partial dentures with magnetic attachment. 2006 [cited 2006 Sep 19] Available from: http://wwwsoc.nii.ac.JP/jmd/international/ $5^{\text {th }} /$ poster/06nakamura/ind.

23. Cecconi. In: Thompson WD, Kratochvil FJ, Caputo AA. Evaluation of photoelastic stress patterns produced by various design of bilateral distal-extension removable partial dentures. J Prosthet Dent 2004;91(2):105-113.

24. Kapur. In: Shifman A, Ben-ur Z. The Mandibular first premolar as an abutment for distalextension removable partial denture: a modified clasp assembly design. J British Dent 2000;188(5):246-48.

25. Sadowsky SJ, Caputo AA. Effect of anchorage system and extension base contact on load transfer with mandibular implant-retained overdentures. J Prosthet Dent 2000;84:327-34

26. Kenney R, Richard MW. Photoelactics stress patterns produced by implant-retained overdenture. J Prostet Dent 1998;80:559-64 